\title{
Editorial 2016
}

\author{
F. Duparc ${ }^{1}$
}

Published online: 12 January 2016

(c) Springer-Verlag France 2016

Seven hundred times thank you!

Dear Anatomists, Clinicians, Researchers,

On behalf of the Editorial Board of Surgical and Radiologic Anatomy, I had been very proud to entitle this editorial "Five Hundred times thank you" in January 2013, after having received more than 500 submissions in 2012. We could not imagine that this development would continue with the same intensity, and that 2015 would record 711 new submitted manuscripts! We are thankful to the authors from 61 countries who considered our journal for submitting their studies.

This continuous increasing editorial activity has been also associated with an important number of reviewers who warranted the quality of our publications through their analysis of the manuscripts. We want to warmly thank the 839 reviewers who completed reviews in 2015.
The Editorial Board has been enlarged as well, for facing the greater activity, and 13 countries from Europe and Asia are now represented in our Board. Special thanks are addressed to the Associate Editors for the great job they do for SRA.

The Congress of the European Association for Clinical Anatomy was held in Rouen, France, in June 2015, as a joint Congress with the British Association of Clinical Anatomists and the Sociedad Anatomica Espaňola. A part of the abstracts of the presentations of this International Congress of Clinical Anatomy are published in this issue.

The researching and publishing in the field of clinical anatomy looks more and more active, and, on behalf of the Editorial Board of SRA, I wish you a very Happy New Year 2016.

Fabrice Duparc, SRA Editor in Chief

\footnotetext{
F. Duparc

fabrice.duparc@univ-rouen.fr

1 Rouen, France
} 